\title{
Global HIV/AIDS Clinical and Translational Pharmacology
}

\author{
Gene D. Morse, ${ }^{1,2,3}$ Gary Maartens, ${ }^{4}$ Charles Chiedza Maponga, ${ }^{1,2,5}$ and Qing Ma ${ }^{1,2,3}$ \\ ${ }^{1}$ Department of Pharmacy Practice, School of Pharmacy and Pharmaceutical Sciences, University at Buffalo, Buffalo, NY 14260, USA \\ ${ }^{2}$ Translational Pharmacology Research Core, New York State Center of Excellence in Bioinformatics and Life Sciences, 701 Ellicot Street, \\ Buffalo, NY 14302, USA \\ ${ }^{3}$ Department of Pharmacology and Physiology, Center for Human Experimental Therapeutics, Clinical and Translational Sciences \\ Institute, University of Rochester School of Medicine and Dentistry, Rochester, NY 14642, USA \\ ${ }^{4}$ Division of Clinical Pharmacology, Department of Medicine, University of Cape Town, Rondebosch 7701, South Africa \\ ${ }^{5}$ School of Pharmacy, College of Health Sciences, University of Zimbabwe, Harare, Zimbabwe
}

Correspondence should be addressed to Gene D. Morse, emorse@buffalo.edu

Received 2 April 2012; Accepted 2 April 2012

Copyright (C) 2012 Gene D. Morse et al. This is an open access article distributed under the Creative Commons Attribution License, which permits unrestricted use, distribution, and reproduction in any medium, provided the original work is properly cited.

The continued development of diagnostic and therapeutic advances for HIV has transformed this once rapidly fatal infection into a chronic disease with an extended lifespan. Initially these benefits were only available to patients in resource-rich countries (RRCs), but since 2003 there has been a global effort through donors and access pricing to provide antiretroviral access to the millions of HIV-infected individuals in resource-limited countries (RLCs) [1-4]. Current combination antiretroviral therapy (cART) achieves viral suppression in a majority of adherent patients [5]. Viral load tests with greater sensitivity have led our appreciation of continued low-level viremia in apparently "suppressed" patients CART while assays that detect latent tissue reservoirs with integrated viral DNA have provided new insight into treatment goals, the source of viral rebound when treatment is interrupted, and the lack of further benefit from treatment intensification [6-11]. A sustained chronic inflammatory state thought to arise in part from translocation of gut microbial products, even during suppressive cART, has led to new mechanistic understanding of chronic ART effects on end organs $[12,13]$. These advances have led to new research efforts to augment suppression with pharmacologic strategies to purge the latent viral reservoirs and reduce translocation of intestinal microbial products, to reduce endorgan disease including cardiovascular, neurologic, renal, and bone. The presence of opportunistic infections such as tuberculosis and coinfections including malaria and viral hepatitis (HCV, HBV), as well as cancer, creates additional diagnostic and therapeutic challenges [14].
Clinical and translational pharmacology researchers have made important contributions to our understanding of the complex relationship between antiretroviral pharmacokinetics, pharmacodynamics, and pharmacogenomics [15-27]. As cART regimens are optimized their use in patients with comorbidities is complicated by pharmacologic challenges that include maintaining medication adherence, preventing and managing drug-drug interactions, identifying optimal doses for malnourished patients, drug toxicity monitoring, and pharmacogenomic testing. Each of these areas contributes to the goal of maximizing ART exposure while minimizing risk factors that lead to complications of chronic cART and concurrent medication use. As a result of efforts to treat as many HIV-infected individuals as possible, the requirement for medications for comorbid diseases, the challenge to conducting relevant clinical pharmacology research as quickly as possible is considerable [28]. Ongoing research in the areas of preexposure prevention with oral ART or vaginal or rectal microbicides, and "treatment as prevention" to reduce new HIV infections, along with nanomedicine strategies, pediatric cART dosing, pregnancy, and geriatric considerations also include therapeutic drug monitoring and novel clinical pharmacology components [29-41].

In this special issue, some of these challenges are addressed. With varied global dietary patterns as well as nutritional status, M. Lamorde et al. report on their investigation of "Effect of food on the steady-state pharmacokinetics of tenofovir, and emtricitabine plus efavirenz in Ugandan adults." Other important patient factors are addressed 
by T. Kakuda et al. in their study of the "Pharmacokinetics and pharmacodynamics of darunavir and etravirine in HIV1-infected, treatment-experienced patients in the gender, race, and clinical experience trial." T. Mudzviti et al. have examined "The impact of herbal drug use on adverse drug reaction profiles of patients on antiretroviral therapy in Zimbabwe" and A. Reda et al. investigated the "Determinants of adherence to antiretroviral therapy among HIV-infected patients in Africa." With regard to coinfections, F. Fehintola et al. studied "nevirapine-based antiretroviral therapy impacts artesunate and dihydroartemisinin disposition in HIV-infected Nigerian adults." W. WirachMaek-a-nantawat et al. have provided a review of "Challenges in providing treatment and care for viral hepatitis among individuals co-infected with HIV in resourcelimited settings." Lastly, in a comprehensive review article K. Dooley et al. have reported on "TB and HIV therapeutics: pharmacology research priorities.”

In summary, this issue provides some excellent examples of research groups that are leading the way while additional planning and capacity building proceed. The need to conduct clinical pharmacology research is essential and will require expanding research facilities with instrumentation and training for the next generation of researchers in this field. The conduct of this comprehensive research agenda will be facilitated through planning of a global, translational pharmacology research effort that includes academic, industrial, regulatory, and community partnerships in RRCs and RLCs. The need for human and laboratory capacity building integrated with a comprehensive clinical pharmacology quality assurance program is significant and should be further integrated with research planning and implementation on a global scale. This approach is likely to accelerate the use of new treatments in countries that are most impacted by HIV and other infectious diseases within the global community. The Fogarty International Center at the National Institutes of Health in the United States, along with other international research funders like the Wellcome Trust and the European and Developing Countries Clinical Trials Partnership, is training current and future global health scientists. The mechanism for building new research centers with state of the art instrumentation remains a challenge to meeting clinical pharmacology research needs around the world. Development of a plan to address these needs is the focus of an annual workshop at the International AIDS Conference and has provided a forum for discussion, needs assessment, and strategic planning to advance this effort.

\section{Acknowledgments}

Drs. G. Morse and C. Maponga are supported in part by Award no. D43TW007991 from the National Institutes of Health Fogarty International Center. Dr. G. Morse is supported in part by the ACTG HIV Pharmacology Specialty Laboratory (Award no. U01AI068636-06) and HIV Clinical Pharmacology Quality Assurance Program (Contract no. HHSN272200800019C) from the National Institute of Allergy and Infectious Diseases and the University of Rochester, Center for Human Experimental Therapeutics,
Rochester, NY, USA. Dr. G. Maartens is supported in part by the ACTG HIV International Pharmacology Specialty Laboratory (Award no. UM1 AI068636-06). Dr. CC Maponga is partially supported by the ACTG HIV International Pharmacology Specialty Laboratory (Award no.BRS-ACURE-S 11000079-001373.

Gene D. Morse
Gary Maartens
Charles Chiedza Maponga
Qing Ma

\section{References}

[1] V. D. Lima, K. Johnston, R. S. Hogg et al., "Expanded access to highly active antiretroviral therapy: a potentially powerful strategy to curb the growth of the HIV epidemic," Journal of Infectious Diseases, vol. 198, no. 1, pp. 59-67, 2008.

[2] J. S. Montaner, R. Hogg, E. Wood et al., "The case for expanding access to highly active antiretroviral therapy to curb the growth of the HIV epidemic," The Lancet, vol. 368, no. 9534, pp. 531-536, 2006.

[3] E. Wood, J. S. G. Montaner, D. R. Bangsberg et al., "Expanding access to HIV antiretroviral therapy among marginalized populations in the developed world," AIDS, vol. 17, no. 17, pp. 2419-2427, 2003.

[4] A. Sarna and S. Kellerman, "Access to antiretroviral therapy for adults and children with HIV infection in developing countries: horizons studies, 2002-2008," Public Health Reports, vol. 125, no. 2, pp. 305-315, 2010.

[5] T.R. Glass, M. Rotger, A. Telenti et al., "Determinants of sustained viral suppression in HIV-infected patients with selfreported poor adherence to antiretroviral therapy," PLOS ONE, vol. 7, no. 1, Article ID e29186, 2012.

[6] R. T. Gandhi, R. W. Coombs, E. S. Chan et al., "No effect of raltegravir intensification on viral replication markers in the blood of HIV-1-infected patients receiving antiretroviral therapy," JAIDS, vol. 59, no. 3, pp. 229-235, 2011.

[7] J. B. Dinoso, S. Y. Kim, A. M. Wiegand et al., "Treatment intensification does not reduce residual HIV-1 viremia in patients on highly active antiretroviral therapy," Proceedings of the National Academy of Sciences of the United States of America, vol. 106, no. 23, pp. 9403-9408, 2009.

[8] R. F. Siliciano, "Latency and reservoirs for HIV-1," AIDS, vol. 13, supplement A, pp. S49-58, 1999.

[9] M. Z. Smith, F. Wightman, and S. R. Lewin, "HIV reservoirs and strategies for eradication," Current HIV/AIDS Reports, vol. 9, no. 1, pp. 5-15, 2012.

[10] T. W. Chun, D. Murray, J. S. Justement et al., "Relationship between residual plasma viremia and the size of HIV proviral DNA reservoirs in infected individuals receiving effective antiretroviral therapy," Journal of Infectious Diseases, vol. 204, no. 1, pp. 135-138, 2011.

[11] T. W. Chun and A. S. Fauci, "Latent reservoirs of HIV: obstacles to the eradication of virus," Proceedings of the National Academy of Sciences of the United States of America, vol. 96, no. 20, pp. 10958-10961, 1999.

[12] J. M. Brenchley, D. A. Price, T. W. Schacker et al., "Microbial translocation is a cause of systemic immune activation in chronic HIV infection," Nature Medicine, vol. 12, no. 12, pp. 1365-1371, 2006.

[13] G. Marchetti, A. Cozzi-Lepri, E. Merlini et al., "Microbial translocation predicts disease progression of HIV-infected 
antiretroviral-naive patients with high CD4+ cell count," AIDS, vol. 25, no. 11, pp. 1385-1394, 2011.

[14] V. Soriano, M. Puoti, M. Sulkowski et al., "Care of patients coinfected with HIV and hepatitis C virus: 2007 updated recommendations from the HCV-HIV International Panel," AIDS, vol. 21, no. 9, pp. 1073-1089, 2007.

[15] J. E. Rower, A. Meditz, E. M. Gardner et al., "Effect of HIV1 infection and sex on the cellular pharmacology of the antiretroviral drugs zidovudine and lamivudine," Antimicrobial Agents and Chemotherapy, vol. 56, no. 6, pp. 3011-3019, 2012.

[16] P. L. Anderson, J. J. Kiser, E. M. Gardner, J. E. Rower, A. Meditz, and R. M. Grant, "Pharmacological considerations for tenofovir and emtricitabine to prevent HIV infection," Journal of Antimicrobial Chemotherapy, vol. 66, no. 2, Article ID dkq447, pp. 240-250, 2011.

[17] J. J. Kiser, C. L. Aquilante, P. L. Anderson, T. M. King, M. L. Carten, and C. V. Fletcher, "Clinical and genetic determinants of intracellular tenofovir diphosphate concentrations in HIVinfected patients," Journal of Acquired Immune Deficiency Syndromes, vol. 47, no. 3, pp. 298-303, 2008.

[18] M. Boffito, E. Acosta, D. Burger et al., "Current status and future prospects of therapeutic drug monitoring and applied clinical pharmacology in antiretroviral therapy," Antiviral Therapy, vol. 10, no. 3, pp. 375-392, 2005.

[19] Q. Ma, B. S. Zingman, A. E. Luque et al., "Therapeutic drug monitoring of protease inhibitors and efavirenz in HIVinfected individuals with active substance-related disorders," Therapeutic Drug Monitoring, vol. 33, no. 3, pp. 309-314, 2011.

[20] M. Albrecht, A. Lisa Mukherjee, C. Tierney et al., "A randomized clinical trial evaluating therapeutic drug monitoring (TDM) for protease inhibitor-based regimens in antiretroviral-experienced HIV-infected individuals: week 48 results of the A5146 study," HIV Clinical Trials, vol. 12, no. 4, pp. 201-214, 2011.

[21] D. Haas, D. Kuritzkes, M. Ritchie et al., "Pharmacogenomics of HIV therapy: summary of a workshop sponsored by the National Institute of allergy and infectious diseases," HIV Clinical Trials, vol. 12, no. 5, pp. 277-285, 2011.

[22] H. J. Ribaudo, H. Liu, M. Schwab et al., "Effect of CYP2B6, $\mathrm{ABCB} 1$, and CYP3A5 polymorphisms on efavirenz pharmacokinetics and treatment response: an AIDS clinical trials group study," Journal of Infectious Diseases, vol. 202, no. 5, pp. 717-722, 2010.

[23] G. D. Morse, L. M. Catanzaro, and E. P. Acosta, "Clinical pharmacodynamics of HIV-1 protease inhibitors: use of inhibitory quotients to optimise pharmacotherapy," The Lancet Infectious Diseases, vol. 6, no. 4, pp. 215-225, 2006.

[24] E.H. Decloedt, G. Maartens, P. Smith, C. Merry, F. Bango, and H. McIlleron, "The safety, effectiveness and concentrations of adjusted lopinavir/ritonavir in HIV-infected adults on rifampicin-based antitubercular therapy," PLOS ONE, vol. 7, no. 3, Article ID e32173, 2012.

[25] T. Kredo, K. Mauff, J. S. Van Der Walt et al., "Interaction between artemether-lumefantrine and nevirapine-based antiretroviral therapy in HIV-1-infected patients," Antimicrobial Agents and Chemotherapy, vol. 55, no. 12, pp. 5616-5623, 2011.

[26] E. H. Decloedt, H. McIlleron, P. Smith, C. Merry, C. Orrell, and G. Maartens, "Pharmacokinetics of lopinavir in HIV-infected adults receiving rifampin with adjusted doses of lopinavir-ritonavir tablets," Antimicrobial Agents and Chemotherapy, vol. 55, no. 7, pp. 3195-3200, 2011.
[27] Y. Ren, J. J. C. Nuttall, B. S. Eley et al., "Effect of rifampicin on efavirenz pharmacokinetics in HIV-infected children with tuberculosis," Journal of Acquired Immune Deficiency Syndromes, vol. 50, no. 5, pp. 439-443, 2009.

[28] C. C. Maponga, Q. Ma, J. C. Slish, and G. D. Morse, "HIV pharmacotherapy issues, challenges, and priorities in subSaharan African countries," Topics in HIV Medicine, vol. 15, no. 3, pp. 104-110, 2007.

[29] C. W. Hendrix, J. C. Ying, and E. J. Fuchs, "Topical microbicides to prevent HIV: clinical drug development challenges," Annual Review of Pharmacology and Toxicology, vol. 49, pp. 349-375, 2009.

[30] W. Heneine and A. Kashuba, "HIV prevention by oral preexposure prophylaxis," Cold Spring Harbor Perspectives in Medicine, vol. 2, no. 3, Article ID a007419, 2012.

[31] K. B. Patterson, H. A. Prince, E. Kraft et al., "HIV. Penetration of tenofovir and emtricitabine in mucosal tissues: implications for prevention of HIV-1 transmission," Science Translational Medicine, vol. 3, no. 112, Article ID 112re4, 2011.

[32] A. D. Kashuba, K. B. Patterson, J. B. Dumond, and M. S. Cohen, "Pre-exposure prophylaxis for HIV prevention: how to predict success," The Lancet. In press.

[33] B. M. Best, S. L. Letendre, P. Koopmans et al., "Low cerebrospinal fluid concentrations of the nucleotide HIV reverse transcriptase inhibitor, tenofovir," Journal of Acquired Immune Deficiency Syndromes, vol. 59, no. 4, pp. 376-381, 2012.

[34] W. Prasitsuebsai, T. R. Cressey, E. Capparelli, N. Vanprapar, K. Lapphra, and K. Chokephaibulkit, "Pharmacokinetics of nevirapine in HIV and tuberculosis-coinfected children receiving antiretroviral fixed-dose combination tablets while receiving rifampicin-containing tuberculosis treatment and after rifampicin discontinuation," Pediatric Infectious Disease Journal, vol. 31, no. 4, pp. 389-391, 2012.

[35] N. Y. Rakhmanina, E. V. Capparelli, and J. N. Van Den Anker, "Personalized therapeutics: HIV treatment in adolescents," Clinical Pharmacology and Therapeutics, vol. 84, no. 6, pp. 734-740, 2008.

[36] S. D. Mahajan, R. Aalinkeel, J. L. Reynolds et al., "Nanotherapeutics using an HIV-1 poly A and transactivator of the HIV-1 LTR-(TAR-) specific siRNA," Pathology Research International, vol. 2011, Article ID 719139, 9 pages, 2011.

[37] M. S. Meltzer, M. Nakamura, B. D. Hansen, J. A. Turpin, D. C. Kalter, and H. E. Gendelman, "Macrophages as susceptible targets for HIV infection, persistent viral reservoirs in tissue, and key immunoregulatory cells that control levels of virus replication and extent of disease," AIDS Research and Human Retroviruses, vol. 6, no. 8, pp. 967-971, 1990.

[38] B. J. Dong, Y. zheng, M. D. Hughes et al., "Nevirapine (NVP) pharmacokinetics (PK) and risk of rash and hepatitis among HIV-infected Sub-Saharan African women," AIDS, vol. 7, no. 26, pp. 833-841, 2012.

[39] M. A. Vogler, K. Patterson, L. Kamemoto et al., "Contraceptive efficacy of oral and transdermal hormones when co-administered with protease inhibitors in HIV-1-infected women: pharmacokinetic results of ACTG trial A5188," Journal of Acquired Immune Deficiency Syndromes, vol. 55, no. 4, pp. 473-482, 2010.

[40] F. T. Aweeka, A. Stek, B. M. Best et al., "Lopinavir protein binding in HIV-1-infected pregnant women," HIV Medicine, vol. 11, no. 4, pp. 232-238, 2010.

[41] A. Yilmaz, M. Gisslén, S. Spudich et al., "Raltegravir cerebrospinal fluid concentrations in HIV-1 infection," PLoS ONE, vol. 4, no. 9, Article ID e6877, 2009. 


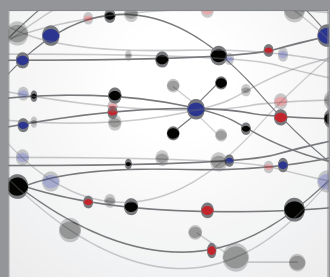

The Scientific World Journal
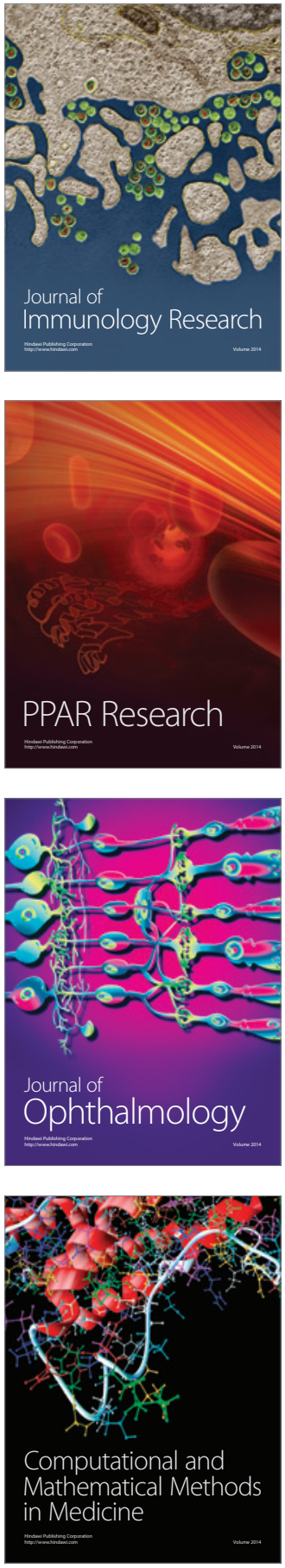

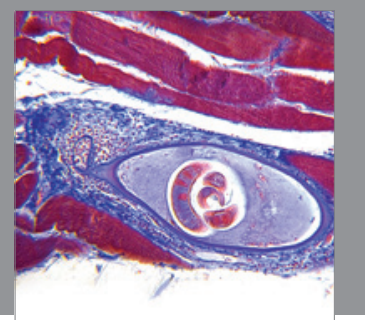

Gastroenterology

Research and Practice
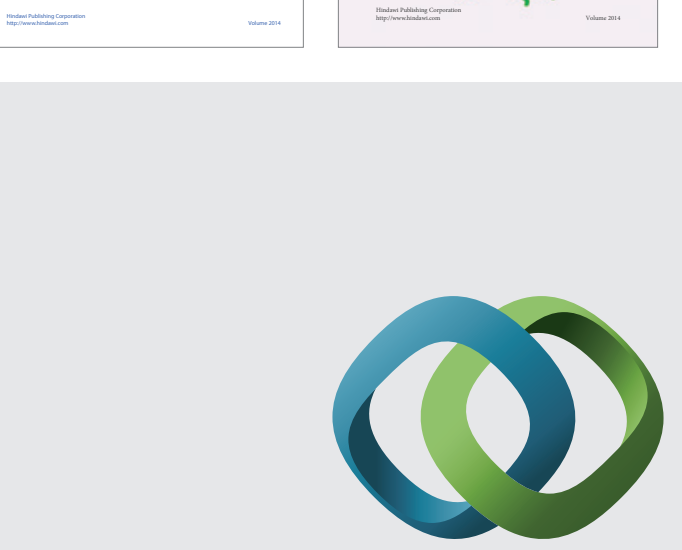

\section{Hindawi}

Submit your manuscripts at

http://www.hindawi.com
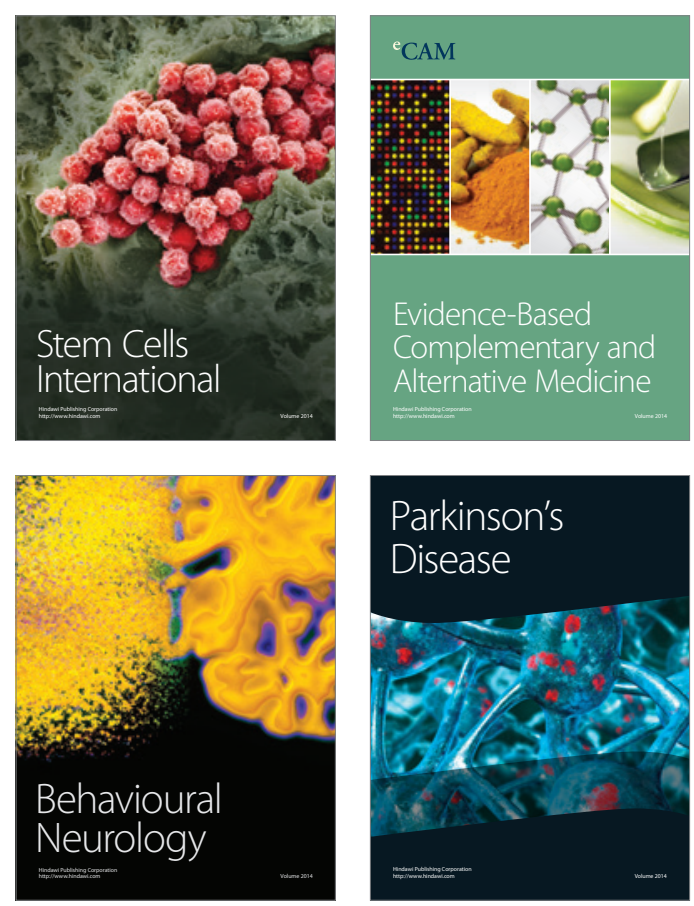

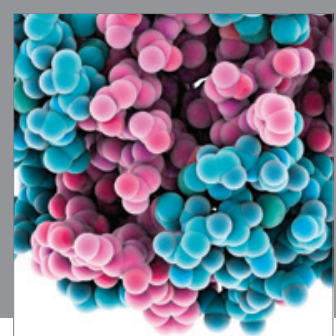

Journal of
Diabetes Research

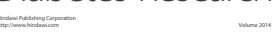

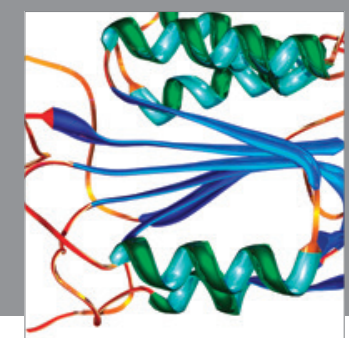

Disease Markers
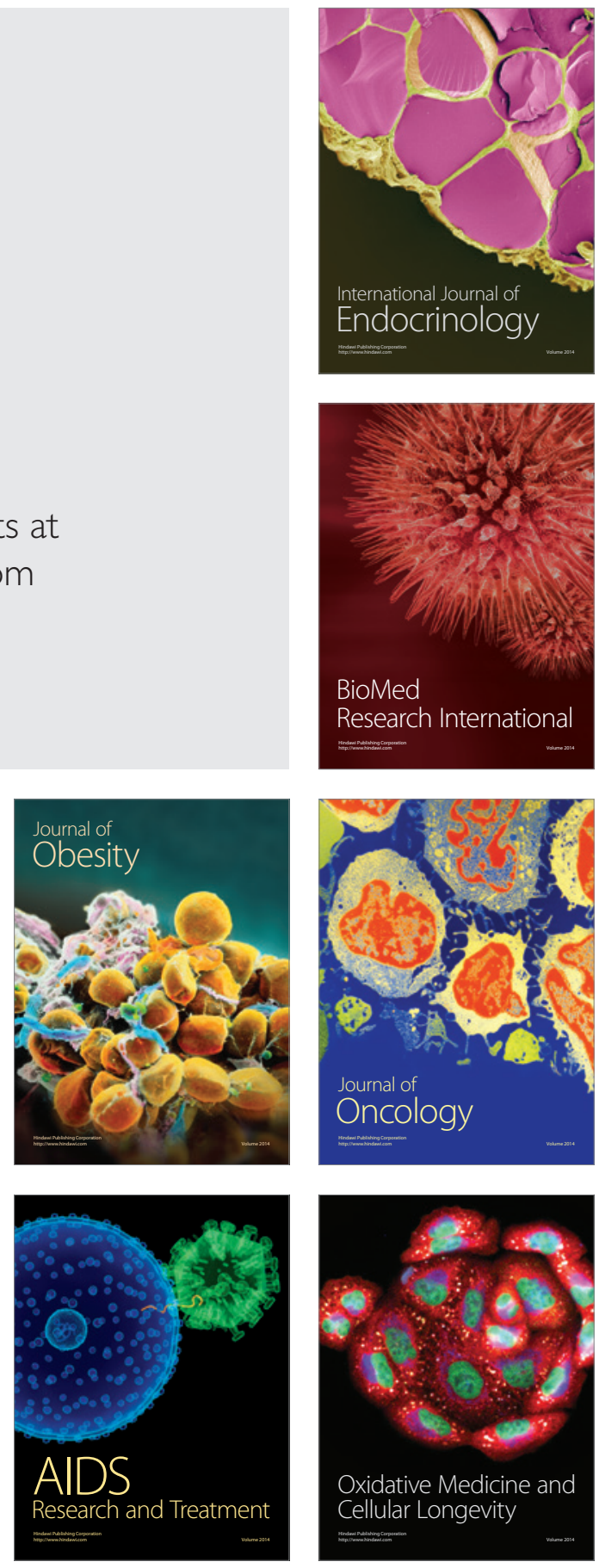